\title{
MANEJO FITOSSANITÁRIO AGROECOLÓGICO EM BARRAGEM SUBTERRÂNEA EM RAJADA, MUNICÍPIO DE PETROLINA, PE
}

\section{PHYTOSANITARY AGROECOLOGICAL MANAGEMENT IN UNDERGROUND DAM IN THE DISTRICT RAJADA, MUNICIPALITY OF PETROLINA, PE, BRAZIL}

Apresentação: Pôster

Anderson Ramos de Oliveira; Roseli Freire de Melo; João Marcos Rodrigues dos Santos

\section{Introdução}

O manejo fitossanitário se reveste da maior importância em sistemas de base agroecológica. Nestes sistemas, a estratégia que norteia a tomada de decisão do agricultor acerca do controle de doenças, pragas ou de plantas daninhas deve ser holística, considerando o equilíbrio do agroecossistema, adotando-se práticas sustentáveis de manejo de forma a reduzir o impacto ambiental provocado por defensivos agrícolas sobre o solo, a água, os animais e as plantas.

Em um sistema agrícola estabelecido em barragem subterrânea, a adoção de práticas fitossanitárias agroecológicas apresenta vantagens para o agricultor, uma vez que os produtos obtidos (oriundos da atividade agrícola) garantem maior segurança alimentar para a família; possibilitam a comercialização do excedente com margem de lucro maior do que o produto proveniente de agricultura convencional, além da redução de custos com adubos químicos e agrotóxicos. De acordo com Nodari e Guerra (2015), os benefícios da prática agroecológica envolvem, ainda, aspectos sociais e de saúde, pois, ao aumentar a renda com a comercialização dos produtos, reduzem-se o êxodo rural e a pobreza, além de melhoria na qualidade de vida com o consumo de alimentos mais saudáveis e nutritivos. Deve-se acrescentar aos benefícios, o aspecto ecológico, com a redução dos agentes poluidores da água e do solo.

Em estudo realizado por Ferreira et al. (2016) sobre a reeducação do manejo fitossanitário, verificou-se que a proposta agroecológica se apresenta com práticas ambientais e sociais justas, sendo que a extensão participativa em agroecologia é fator crucial na disseminação de saberes agroecológicos, possibilitando que agricultores realizem mudanças 
na maneira de utilizar recursos naturais, buscando-se manejo fitossanitário mais sustentável e, consequentemente, melhor qualidade de vida e desenvolvimento social.

Uma abordagem utilizada em agroecologia é a pesquisa participativa que, muitas das vezes, se inicia com a aplicação de questionários nas fases de aproximação com as comunidades e de diagnóstico (DAL SOGLIO, 2017). Segundo Chaer et al. (2011), o questionário é uma técnica bastante viável e pertinente para ser empregada quando se trata de problemas cujos objetos de pesquisa correspondem a questões de cunho empírico, envolvendo opinião, percepção, posicionamento e preferências dos pesquisados.

O objetivo deste estudo foi diagnosticar, por meio de pesquisa participativa com agricultor de base familiar, a adoção de práticas agroecológicas de manejo fitossanitário em cultivos consorciados em barragem subterrânea no Distrito de Rajada, em Petrolina, PE.

\section{Fundamentação Teórica}

A barragem subterrânea é uma tecnologia de captação e de armazenamento de água de chuva que tem como fundamento principal impedir o fluxo subterrâneo de um aquífero préexistente e, ou o fluxo superficial da água em uma bacia hidrográfica, por meio da construção de uma parede impermeável, resultando em manutenção da umidade no solo por período superior ao que ocorre no ambiente externo à barragem, o que permite a exploração agrícola com menores riscos e com aumentos significativos da produtividade (MELO et al., 2013; SOUSA et al., 2014). Tal tecnologia, aliada à prática agroecológica, aumenta a possibilidade de sucesso com a atividade agrícola em áreas dependentes de chuva.

A agroecologia se apresenta com enfoque científico transdisciplinar. Contudo, envolve conhecimentos, saberes e experiências dos próprios agricultores, o que permite o estabelecimento de um conjunto de conceitos e simbologias, abordagens metodológicas e planejamento de ações com maior capacidade para orientar o desenho e o manejo dos agroecossistemas mais sustentáveis, além de considerar processos e práticas rurais que envolvam melhores condições para os agricultores (CAPORAL, 2009). Na busca por agroecossistemas mais sustentáveis, o manejo fitossanitário tem papel relevante.

Em barragem subterrânea, diversas tecnologias fitossanitárias fundamentadas na prática agroecológica e utilizadas em sistemas tanto de agricultura convencional quanto de agricultura orgânica podem ser aplicadas, sendo que as mesmas podem estar atreladas às modalidades de manejo preventivo, cultural, biológico e ao manejo integrado de pragas, de 
doenças e de plantas daninhas (SOUZA, 2015; TARTARIN et al., 2017; COSTA et al., 2018).

\section{Metodologia}

O estudo foi desenvolvido em uma barragem subterrânea, com sete anos de uso, localizada em propriedade de agricultor familiar do Sítio Romão, no Distrito de Rajada, município de Petrolina, PE. O solo da área foi classificado como Neossolo Flúvico psamítico. Segundo a classificação de Köppen, a região se caracteriza por apresentar clima do tipo BShw, ou seja, semiárido quente com curta estação chuvosa no verão. A pluviosidade é baixa e irregular, com média de $470 \mathrm{~mm}^{\mathrm{ano}}{ }^{-1}$, e temperatura média anual de $26,2{ }^{\circ} \mathrm{C}$.

O acompanhamento das atividades agrícolas foi realizado por um período de dois anos consecutivos (2016 e 2017). Na barragem subterrânea, foram cultivadas diversas espécies em sistemas consorciados do tipo misto, que é o plantio simultâneo de duas ou mais culturas na mesma área, sem organizá-las em fileiras distintas (SOARES \& PORTES, 2014).

O agricultor (familiar) utilizou adubo orgânico (esterco caprino) para suprir as necessidades nutricionais dos cultivos. A adubação foi realizada no início do período chuvoso de cada ano, depositando-se o esterco, em quantidade aproximada de, 2,0 litros por metro linear.

A aplicação de água suplementar, proveniente de cisterna tipo calçadão, foi realizada nos períodos de ocorrência de veranicos, buscando-se manter o solo com umidade entre $30 \%$ e $40 \%$. Após cada evento de chuva, a aplicação da água suplementar foi suspensa. A precipitação pluviométrica foi monitorada durante o período de estudo com a instalação de um pluviômetro na área da barragem. O volume precipitado em 2016 foi de $280 \mathrm{~mm}$ e em 2017 foi de $375 \mathrm{~mm}$.

$\mathrm{Na}$ propriedade, a abordagem metodológica utilizada com o agricultor foi a do "Desenvolvimento Participativo de Tecnologias" que, segundo Dal Soglio (2017), prevê o diagnóstico dos problemas e das oportunidades e promove a interação entre os pesquisadores e o agricultor familiar, tendo em vista o compartilhamento de resultados, levando-se em consideração a autonomia do agricultor na tomada decisão. Para o diagnóstico fitossanitário, foi utilizada uma entrevista semiestruturada em profundidade (GIL, 2011) que permitiu, ao mesmo tempo, a liberdade de expressão do agricultor e a manutenção do foco do entrevistador. 


\section{Resultados e Discussões}

Os cultivos realizados durante o período de avaliação foram: feijão-caupi, milho, macaxeira, cana-de-açúcar, sorgo, coentro, pimentão, mandacaru sem espinho, palma, cebola, tomate, batata-doce, mamão e abóbora (Figura 1). Constatou-se, mediante a aplicação da entrevista semiestruturada, que o agricultor utiliza diversas tecnologias de manejo que favorecem o desenvolvimento da cultura e que minimizam os efeitos dos fitopatógenos, dos insetos nocivos aos cultivos e das plantas daninhas.

Uma das principais tecnologias de manejo cultural adotada pelo agricultor é o cultivo consorciado de espécies (Figura 2), que aumenta o número de inimigos naturais e reduz o risco de ataques severos como os que ocorrem em monocultivos. O agricultor utiliza de outras técnicas que auxiliam na manutenção dos cultivos livres de agentes prejudiciais, como a rotação de culturas, a adequada época de plantio, a seleção de material (cultivar) adaptado à região, a adubação com esterco caprino curtido, o uso de adubos verdes, o emprego de cobertura morta, as práticas de capina manual e roçagem, dentre outras.

Figura 1: Vista parcial da barragem subterrânea com cultivo de abóbora. Fonte: Própria

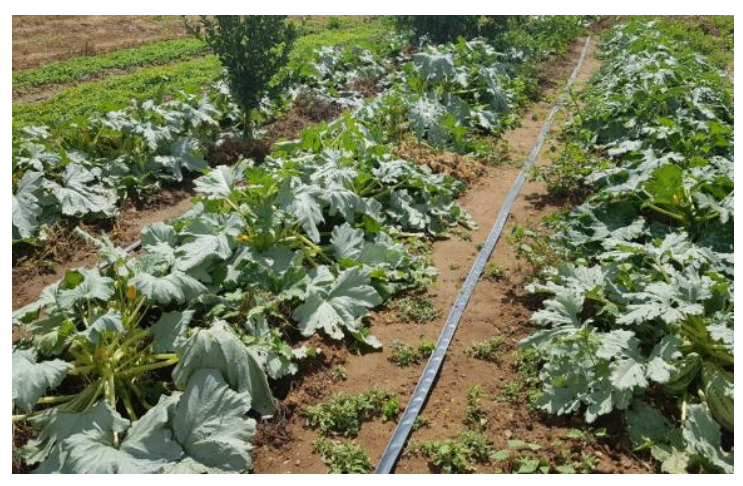

Figura 2: Vista parcial do consórcio de culturas em barragem subterrânea. Fonte: Própria

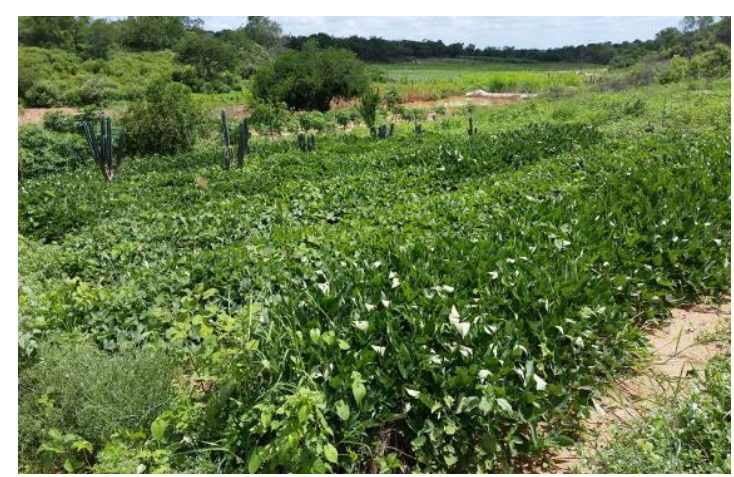

Alguns fertilizantes podem, além de exercer seu papel nutricional, auxiliar no controle de pragas e doenças, como é o caso do enxofre. Na agricultura orgânica, por exemplo, o uso de enxofre elementar é permitido via aplicação de gesso e em formulações para fertilização. Tal produto pode ser utilizado na cultura da cebola, por exemplo, para controle de tripes.

$\mathrm{O}$ agricultor utilizou o manejo preventivo para evitar que sementes e outros materiais de propagação pudessem veicular a entrada de contaminantes para a área da barragem subterrânea. Para isto, foram utilizadas sementes certificadas de feijão-caupi, de milho, de hortaliças, de mamão e de sorgo, garantindo maior qualidade e segurança. 
Dentre os cultivos, apenas o tomate, a abóbora e o milho apresentaram sintomas de ataques de pragas, tendo a mosca-branca (Bemisia tabaci) e a lagarta (Diaphania sp.) sido as de maior ocorrência. O agricultor utilizou, para controle da mosca-branca, uma mistura caseira à base de farinha de trigo, óleo e detergente. Além disso, pulverizou extrato de nim, também de preparo caseiro, para manejo das populações da lagarta nas culturas de abóbora e de tomate. No milho, não foi necessário o uso de controle, pois a incidência da lagarta foi reduzida e os danos causados foram inferiores ao dano econômico. Souza (2015), Tartarin et al. (2017) e Costa et al. (2018) relatam que, além do uso de preparados caseiros com extratos de plantas que tenham efeitos alelopáticos, a calda sulfocálcica e a calda bordalesa, assim como os (ou alguns) bioinseticidas, podem auxiliar no controle de pragas e de doenças, principalmente em cultivos agroecológicos.

Em relação às plantas daninhas, o agricultor informou que o bredo ou caruru (Amaranthus sp.) e o capim carrapicho (Cenchrus echinatus L.) foram os de ocorrência mais frequente. Para o controle destas plantas invasoras, o agricultor realizou a capina manual, sendo que as plantas foram amontoadas e depois foram fornecidas para a alimentação dos caprinos da propriedade.

$\mathrm{O}$ aspecto mais relevante do cultivo em barragem subterrânea, utilizando-se práticas agroecológicas no manejo fitossanitário, foi o equilíbrio proporcionado pelo manejo integrado, que reduziu os agentes causadores de danos. Tal manejo está diretamente relacionado às práticas sustentáveis utilizadas pelo agricultor ao longo dos sete anos em que desenvolve suas atividades naquela barragem.

\section{Conclusões}

$\checkmark$ As práticas fitossanitárias adotadas pelo agricultor familiar na barragem subterrânea conduzem ao equilíbrio do agroecossistema e fundamentam-se na adoção de métodos de controle de pragas, de doenças e de plantas daninhas dentro da vertente agroecológica.

$\checkmark$ A prática de cultivo consorciado, por si só, já se constitui em importante método facilitador do equilíbrio, contribuindo para a redução dos problemas fitossanitários.

$\checkmark$ O agricultor utiliza métodos de controle preventivo, de controle cultural (cobertura morta, capina manual e roçagem, pulverização com extratos naturais para controle de pragas), além de manejo nutricional com esterco caprino, a fim de garantir maior resistência dos cultivos aos estresses bióticos. 


\section{Referências}

CAPORAL, F. R. Agroecologia: uma nova ciência para apoiar a transição a agriculturas mais sustentáveis. In: CAPORAL, F. R.; COSTABEBER, J. A.; PAULUS, G. (Org.). Agroecologia: uma ciência do campo da complexidade. Brasília: MDA/SAF, 2009, p. 9-64.

CHAER, G.; DINIZ, R. R. P.; RIBEIRO, E. A. A técnica do questionário na pesquisa educacional. Evidência, v. 7, n. 7, p. 251-266, 2011.

COSTA, N. V.; COSTA, A. C. P. R.; COELHO, E. M. P.; FERREIRA, S. D.; BARBOSA, J. A. Métodos de controle de plantas daninhas em sistemas orgânicos: breve revisão. Revista Brasileira de Herbicidas, v. 17, n. 1, p. 25-44, 2018.

DAL SOGLIO, F. K. Princípios e aplicações da pesquisa participativa em agroecologia. Redes - Revista do Desenvolvimento Regional, v. 22, n. 2, p. 116-136, 2017.

FERREIRA, T. C.; CUNHA, A. L. A.; LEÃO, A. C. Reeducação do manejo fitossanitário das principais culturas agrícolas da Comunidade do Almeida - Lagoa Seca, PB. Revista Gestão \& Sustentabilidade Ambiental, v. 4, n. 2, p. 369-385, 2016.

GIL, A. C. Métodos e técnicas de pesquisa social. 6.ed. São Paulo: Atlas, 2011.200 p.

MELO, R. F.; ANJOS, J. B.; SILVA, M. S. L.; PEREIRA, L. A.; BRITO, L. T. L. Barragem subterrânea: tecnologia para armazenamento de água e produção de alimentos. Petrolina: Embrapa Semiárido, 2013. (Embrapa Semiárido. Instruções Técnicas, 104).

NODARI, R. O.; GUERRA, M. P. A agroecologia: estratégias de pesquisa e valores. Estudos Avançados, v. 29, n.83, p. 183-207, 2015.

SOARES, D. M.; PORTES, T. A. Consórcio. In: GONZAGA, A. C. O. (Ed.). Feijão: o produtor pergunta, a Embrapa responde. 2. ed. Brasília: Embrapa, 2014, p. 89-96.

SOUSA, T. P.; SOUSA NETO, E. P.; SILVEIRA, L. R. S.; SANTOS FILHO, E. F.; MARACAJÁ, P. B. Barragem subterrânea: tecnologia sustentável de captação, armazenamento de água e convívio com o semiárido. Revista Terceiro Incluído, v. 4, n.1, p. 97-103, 2014.

SOUZA, J. L. Agroecologia e agricultura orgânica: princípios, métodos e práticas. $2^{\mathrm{a}}$ ed. Vitória: Incaper, 34p. 2015. (Incaper. Documentos, 200).

TARTARIN; B. B. G.; MOTA, J. A.; BARROS, W. S.; OLIVEIRA, T. O. P.; OLIVEIRA, J. A. G. Controle agroecológico de pragas em hortícolas: uma revisão de conceitos e práticas. Revista Conexão Eletrônica, v. 14, n. 1, p. 500-514, 2017. 